\title{
Comparison of the effect of vitamin D on osteoporosis and osteoporotic patients with healthy individuals referred to the Bone Density Measurement Center
}

https://doi.org/10.1515/bmc-2019-0005

received December 21, 2018; accepted February 4, 2019.

\begin{abstract}
:
Objective: Osteoporosis is the most common metabolic disease of the bones. Osteoporosis reduces bone density, predisposes a person to fractures, and imposes high costs on societies. Osteoporosis develops from a variety of causes, one of the most significant is vitamin D deficiency. This study investigates the impact of vitamin D on osteoporosis.
\end{abstract}

Materials and Methods: In this clinical trial, 400 patients referred to the Bone Density Clinic of Kowsar Hospital in Semnan were selected by convenience sampling method. Bone densitometry tests were carried out using DEXA (x-ray absorptiometry) and serum vitamin D levels were measured by the ELISA method. Subjects with vitamin D deficiency were treated for 8 weeks with $(50,000$ Vitamin D units per week. At the end of the treatment period, all subjects were evaluated for bone density and the results of both groups were compared.

Results: $13 \%$ of subjects had osteoporosis and $14.2 \%$ had osteopenia. $19 \%$ of subjects had vitamin D deficiency, $38.8 \%$ had insufficient levels of vitamin D, and $42.3 \%$ had sufficient vitamin D levels. The level of vitamin D in patients with osteoporosis $(5.50 \pm 5.5 \mathrm{ng} / \mathrm{ml})$ was less than those with osteopenia $(7.83 \pm 4.8 \mathrm{ng} / \mathrm{ml})$ and those

*Corresponding author: Majid Foroutan, Internal Medicine Department, School of Medicine, Semnan University of Medical Sciences, Semnan, Iran, E-mail: dr_forotan@yahoo.com Banafsheh Shahnazari: School of Medicine, Tehran University of Medical Sciences, Tehran, Iran

Majid Mirmohammadkhani: Social Determinats of Health Research center, Semnan University of Medical Sciences, Semnan, Iran Amir Ghorbani: Student Research Committee, Semnan University of Medical Sciences, Semnan, Iran with normal bone mineral density $(23.88 \pm 18.42 \mathrm{ng} / \mathrm{ml})$ ( $\mathrm{P}<0.001)$. The prevalence of osteoporosis in the intervention group after intervention with vitamin D was significantly lower than the control group (32.3 versus 67.7 and $\mathrm{P}<0.001$ ).

Conclusion: The prevalence of serum vitamin D deficiency in osteopenic and osteoporotic individuals was higher than in normal subjects, with a significant relationship between age and sex. Thus, treatment with vitamin D improves bone density indices.

Keywords: Bone Density; Vitamin D Deficiency; Osteoporosis; Osteopenia.

\section{Introduction}

Osteoporosis, which can lead to fractures caused by reduction in bone density, is the most common metabolic disease of the bones [1-3]. Osteoporosis is considered a health priority and inflicts a heavy burden on the community.

As such, a high percentage of treatment intervention is allocated to it and the lack of it imposes irreparable costs on the health system [4]. Age-related hip fracture is increasing around the world, possibly due to industrialization and lack of activity. Femoral area (hip) fracture is the main cause of mortality and morbidity in elderly people [2]. This considerable challenge imposes high cost on societies. Screening may greatly reduce this cost [5-8]. The Iranian Osteoporosis Research Center reported that since in most societies, including Iran, life expectancy has increased and people are living longer, the prevalence of osteoporosis is also increasing [4, 9]. Throughout life, older bone is periodically absorbed by osteoclasts in resorption sites and replaced by new bone 
made by osteoblasts. This process is known as remodeling $[10,11]$. Impairment of the regeneration process is the main pathophysiology cause of osteoporosis [12, 13]. Several factors affect developing osteoporosis, including genetic [14], low weight [15], old age and history of broken bones [16], Cushing's syndrome [17], family history of a fractured hip after a minor fall [18], underlying diseases such as rheumatoid arthritis [19], inflammatory bowel disease (IBD) [20], hyperparathyroidism [21], cystic fibrosis [21], hyperthyroidism [22], type 1 and type 2 diabetes [23], and kidney disorders [24].

Aninfluentialfactorinthedevelopmentof osteoporosis is calcium and vitamin D deficiency. The intake of calcium and vitamin D supplements has a significant effect on the prevention and treatment of osteoporosis, especially in elderly people [21]. Some evidence supports the intake of calcium alone or in combination with vitamin D in order to prevent or treat osteoporosis in people aged 50 and older. The results of a meta-analysis aimed at reducing fracture risk showed that calcium intake alone or in combination with vitamin D had a significant effect on the prevention of bone loss and fracture in people 50 years old. The fracture risk in all the subjects decreased by $12 \%$ [25]. The Bone mineral density (BMD) test is available for many patients using the DEXA (dual energy x-ray absorptiometry) method, which is currently the best known method for osteoporosis diagnosis and screening [2]. Diagnosis of osteoporosis depends on the Z-score, which is the comparison of bone density with a person of the same age, gender, and race. This score must be at least equal to or less than -1 , otherwise, the patient is diagnosed with osteoporosis [26].

Treatment of osteoporosis includes two parts. One entails lifestyle changes, such as regular sun exposure, adequate nutrition, and sufficient exercise and activity. The other part consists of pharmacotherapy, including the use of selective estrogen receptor modulators (SERMs) such as raloxifene, calcitonin, fluoride, strontium, parathormone, diphosphates such as alendronate, calcium, and vitamin D as a health priority $[27,28]$. In a study on the important role of zinc and calcium on bone health, nutritional education relating to the consumption of foods containing zinc and calcium is recommended to prevent bone loss in osteoporosis women [29].Vitamin D deficiency is a global public health problem in all age groups, especially in the Middle East [30]. Given that osteoporosis increases the risk of fractures and osteoporotic fracture plays a significant role in mortality, depression, and being bedbound, osteoporosis is an important concern [12, 13]. On the other hand, it is necessary to know the factors that affect the results of BMD tests. The objective of this study was to investigate if the results of 25-hydroxy vitamin D tests as a factor might affect bone density; in a way that by its modification the results of BMD test could be reached to an acceptable level, and there would be no need for pharmacotherapy in osteoporosis treatment. Considering the increased mean age of communities and the high prevalence of osteoporosis, as well as the long term treatment period, the results of this project will play a key role in reducing health costs.

The aim of this study was to compare the prevalence of vitamin D deficiency among osteopenic and osteoporotic patients with healthy individuals, and to investigate the association between vitamin D deficiency and bone densitometry status in these patients.

\section{Materials and Methods}

\section{Design}

This study was carried out with a registration number in a clinical trial on all individuals who were referred to The Bone Density Clinic of Semnan's Kowsar Hospital in Iran, in 2018.

\section{Participants}

Inclusion criteria were being 30 - 60 years old and being fully satisfied with participation in the study. Exclusion criteria were people with a history of chronic glucocorticoid excess, whether endogenous (such as Cushing's syndrome) or exogenous, smoking or consuming alcohol, having rheumatoid arthritis, having IBD, having hyperparathyroidism, having cystic fibrosis, history of hyperthyroidism, having type 1 and type 2 diabetes, or having kidney complications, taking vitamin D pills, being under the supervision of a dietitian and a therapist.

\section{Intervention}

After confirmation of the preliminary plan by the research council of Kowsar University Hospital and after receiving the Ethics Code from the Ethics Committee of Semnan University of Medical Sciences, consent letters for participation in the study were given to the subjects. After presenting the project and describing the objective of the survey, consent letters were filled out and confirmed 
by the participants. Moreover, during filling out the checklists, the description and significance of the study was fully explained to the subjects.

In this study, 400 individuals referred to The Bone Density Clinic of Semnan's Kowsar Hospital in 2018 were selected by a convenience sampling method. Primary data were collected using a checklist containing questions about demographic information including age, gender, clinical examination, and paraclinical information. The data were followed up in the following years and a bone mass density test was performed using the DEXA method. Vitamin D levels in all participants were measured by the 25-hydroxy vitamin D test. In this regard, 3 cc blood samples were taken from the subjects and their serum was separated. Then, using the EUROIMMUN vitamin E test kit (company IDS England) 25-hydroxy vitamin D levels were measured through ELISA method. The level of 25-hydroxy vitamin D was measured by the ELIZA READER device normalized to the standards, with readings taken in $\mathrm{ng} / \mathrm{mL}$. Based on the instructions from the vitamin D kit, the subjects with 25-hydroxy vitamin D levels of less than or equal to $5 \mathrm{ng} / \mathrm{ml}$ were considered as vitamin D deficiency, individuals with serum levels of 25-hydroxy vitamin D between 5.01 to $14.99 \mathrm{ng} / \mathrm{ml}$ were considered as insufficient, and subjects with serum levels of 25-hydroxy vitamin $\mathrm{D}$ found to be equal to or greater than $15 \mathrm{ng} / \mathrm{ml}$ were considered as sufficient. Moreover, subjects with T-scores less than -2.5 were considered to have osteoporosis, individuals with T-scores ranging from -0.1 to -2.5 were considered to have osteopenia, and those with T-scores of greater than or equal to -1.0 were considered as normal individuals. Thereupon, subjects with vitamin D deficiency were treated with Vitamin D capsule for 8 weeks. Subjects in the intervention group received 50000 units of vitamin D per week and the control group received placebo. Treatment continued for 8 weeks for both groups. At the end of the treatment period, all subjects were evaluated for bone density, and the results of both groups were compared. After the completion of the study, those who were deficient or insufficient in vitamin D were treated.

\section{Blinding}

Subjects in the intervention group took 50000 units of vitamin D once a week and the control group took a placebo. Treatment was continued for 8 weeks in both groups and patients did not know whether they took medication or placebo.

\section{Ethical considerations}

The checklists were anonymous and included only raw data and statistics. Subjects were assured that their information would remain confidential. Consent letters were obtained from the subjects and they were assured that, in case of dissatisfaction, each participant could withdraw from the study at any stage of the project. This study was approved with a registration number in a clinical trial by the Ethics Council of Semnan University of Medical Sciences and Health Services.

\section{Statistical methods}

The collected data were analyzed using SPSS software version 23. For statistical description of numerical variables, the mean and standard deviation (SD) were reported, and for categorical variables, count and percentage were reported. Data analysis was done using the Kolmogorov-Smirnov test, paired t-test, Chi-square test, and ANOVA test (comparison of two groups with repeated measures) at significant level of 5\%.

Informed consent: Informed consent has been obtained from all individuals included in this study

Ethics approval: The research related to human use has been complied with all the relevant national regulations, institutional policies and in accordance the tenets of the Helsinki Declaration, and has been approved by the Semnan University of Medical Ethics Committee (IR. SEMUMS. REC. 1396.108).

\section{Results}

Most subjects were in the 31-40 years age group (40.5\%). $51.5 \%$ (206 out of 400) of participants were male and $48.5 \%$ (194 out of 400) were female. According to the results, $19 \%$ of the participants suffered from vitamin D deficiency, 38.8\% had insufficient levels of vitamin D, and 42.3\% had sufficient levels of vitamin D.

In bone density measurement, $13 \%$ of subjects had osteoporosis, $14.2 \%$ had osteopenia, and $72.8 \%$ were normal. The results of data analysis also indicated that there was a significant association between vitamin D level and bone mass density status. The prevalence of vitamin D deficiency in subjects with osteoporosis was $44.7 \%$, in subjects with osteopenia was $28.9 \%$, and in subjects with normal bone density was $26.3 \%(\mathrm{P}<0.001)$. The results showed that there was also a significant relationship 
Table 1: Distribution of vitamin D level and bone density in patients referred to the Bone Density Clinic in the Kowsar Hospital of Semnan during 2017 by age group.

\begin{tabular}{|c|c|c|c|c|c|c|}
\hline \multirow[t]{2}{*}{ Age category } & \multicolumn{2}{|l|}{ Normal } & \multicolumn{2}{|l|}{ Inadequate level } & \multicolumn{2}{|l|}{ Shortage } \\
\hline & $\begin{array}{l}\text { Percentage of } \\
\text { vitamin D levels }\end{array}$ & $\begin{array}{l}\text { Percentage of } \\
\text { bone density }\end{array}$ & $\begin{array}{l}\text { Percentage of } \\
\text { vitamin D levels }\end{array}$ & $\begin{array}{l}\text { Percentage of } \\
\text { vitamin D levels }\end{array}$ & $\begin{array}{l}\text { Percentage of bone } \\
\text { density }\end{array}$ & $\begin{array}{l}\text { Percentage of } \\
\text { vitamin D levels }\end{array}$ \\
\hline $\begin{array}{l}20 \text { to } 30 \\
\text { years }\end{array}$ & 16.0 & 12.4 & 5.8 & - & - & - \\
\hline $\begin{array}{l}31 \text { to } 40 \\
\text { years }\end{array}$ & 65.1 & 54.3 & 32.9 & 5.3 & 1.3 & 1.9 \\
\hline $\begin{array}{l}41 \text { to } 50 \\
\text { years }\end{array}$ & 11.8 & 15.1 & 20.0 & 24.6 & 31.6 & 32.7 \\
\hline $\begin{array}{l}51 \text { to } 60 \\
\text { years }\end{array}$ & 7.1 & 18.2 & 41.3 & 70.2 & 67.1 & 65.4 \\
\hline
\end{tabular}

Table 2: Distribution of vitamin D level and bone density in patients referred to the Bone Density Clinic of Kowsar Hospital of Semnan during 2017 by gender.

\begin{tabular}{lllllll}
\hline Sex & normal & & Inadequate level & & Shortage \\
\cline { 2 - 7 } & $\begin{array}{l}\text { Percentage of } \\
\text { vitamin D levels }\end{array}$ & $\begin{array}{l}\text { Percentage of } \\
\text { bone density }\end{array}$ & $\begin{array}{l}\text { Percentage of } \\
\text { vitamin D levels }\end{array}$ & $\begin{array}{l}\text { Percentage of bone } \\
\text { density }\end{array}$ & $\begin{array}{l}\text { Percentage of } \\
\text { vitamin D levels }\end{array}$ & $\begin{array}{l}\text { Percentage of } \\
\text { bone density }\end{array}$ \\
\hline Male & 49.7 & 46.4 & 41.3 & 54.4 & 60.5 & 53.8 \\
Female & 50.3 & 53.6 & 58.7 & 45.6 & 39.5 & 46.2 \\
\hline
\end{tabular}

between vitamin $\mathrm{D}$ level and age groups $(\mathrm{P}<0.001)$. There was also a significant association between bone density and age groups. The highest prevalence of osteoporosis $(65.4 \%)$ was found in the 51-60 years old age group $(\mathrm{P}<0.001$, Table 1$)$.

There was a significant relationship between vitamin D levels and gender of the subjects. The highest prevalence of vitamin D deficiency (60.5\%) was seen in female subjects $(\mathrm{P}=0.021)$, but the results of data analysis suggested that there was no significant association between bone density and gender $(\mathrm{P}=0.386$, Table 2$)$.

In this study, 76 patients with vitamin D deficiency were treated with vitamin D supplements. After 8 weeks of treatment, their bone density status was compared to those who did not have vitamin D deficiency and were not treated with Vitamin D supplements (324 people). Data analysis indicates that there is a significant difference between the changes in T-score in the two groups according to the repeated measures ANOVA model $(\mathrm{P}<0.001)$. T-score changes in the intervention group were significantly more than the control group (0.81 vs. 0.30 and $\mathrm{P}<0.001)$. Also based on the repeated measures ANOVA model, there was a significant difference between Z-score changes in two groups $(\mathrm{P}<0.001)$. $Z$-score changes in the intervention

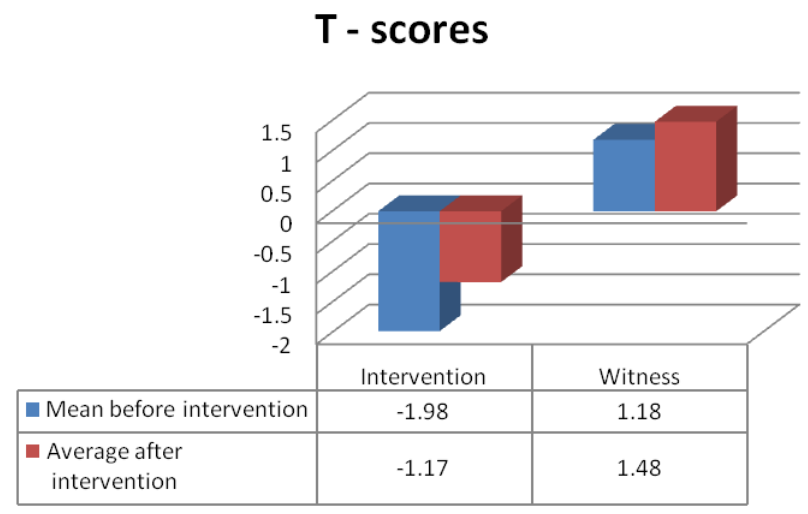

Figure1: Line chart of T-score changes of bone density in patients referred to The Bone Density Clinic of Semnan's Kowsar Hospital in 2018 , by intervention and control groups.

group were significantly more than the control group (0.56 vs. 0.32 and $\mathrm{P}<0.001$, Figures 1 and 2).

It was shown that the prevalence of osteoporosis in the intervention group after administration of vitamin D was significantly lower than the control group (32.3 vs. 67.7 and $\mathrm{P}<0.001$, Table 3 ). 
Table 3: Count distribution and frequency percentage of different statuses in BMD test of patients referred to The Bone Density Clinic of Semnan's Kowsar Hospital in 2018, by intervention and control groups.

\begin{tabular}{|c|c|c|c|c|c|c|}
\hline \multicolumn{7}{|c|}{ Bone density status: count (\%) } \\
\hline \multirow[b]{2}{*}{ Group } & \multicolumn{2}{|l|}{ Normal ( $\geq-1)$} & \multicolumn{2}{|c|}{ Osteopenia (-1 to -2.5$)$} & \multicolumn{2}{|c|}{ Osteoporosis $(\leq-2.5)$} \\
\hline & $\begin{array}{l}\text { Before } \\
\text { intervention }\end{array}$ & After intervention & $\begin{array}{l}\text { Before } \\
\text { intervention }\end{array}$ & $\begin{array}{l}\text { After } \\
\text { intervention }\end{array}$ & $\begin{array}{l}\text { Before } \\
\text { intervention }\end{array}$ & $\begin{array}{l}\text { After } \\
\text { intervention }\end{array}$ \\
\hline Intervention & $20(6.9 \%)$ & $34(10.5 \%)$ & $22(38.6 \%)$ & $21(47.7 \%)$ & $34(65.4 \%)$ & $10(32.3 \%)$ \\
\hline Control & $271(93.1 \%)$ & $291(89.5 \%)$ & $35(61.4 \%)$ & $23(52.3 \%)$ & $34(65.4 \%)$ & $21(67.7 \%)$ \\
\hline Total & $291(100 \%)$ & $325(100 \%)$ & $57(100 \%)$ & $44(100 \%)$ & $52(100 \%)$ & $31(100 \%)$ \\
\hline
\end{tabular}

\section{Z- scores}

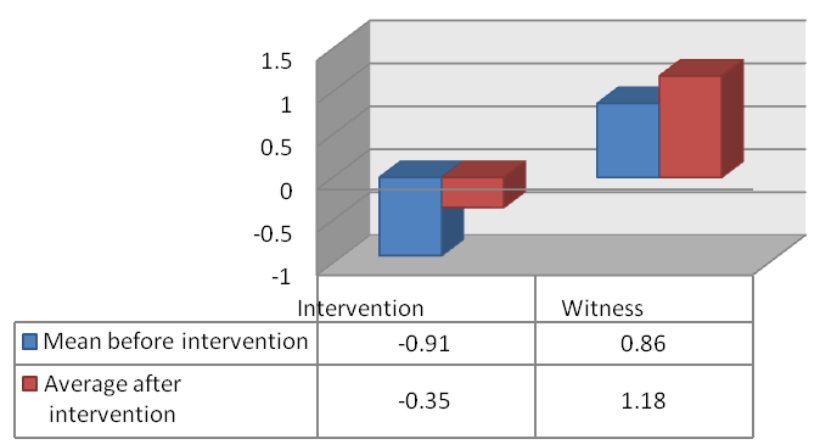

Figure 2: Line chart of Z-score changes of bone density in patients referred to The Bone Density Clinic of Semnan's Kowsar Hospital in 2018 , by intervention and control groups.

\section{Discussion}

Data analysis demonstrated that $13 \%$ of subjects had osteoporosis and $14.2 \%$ had osteopenia. In previous studies conducted in Iran, it was found that the prevalence of osteoporosis in different cities is heterogeneous. In a study done in Yazd, the prevalence of osteoporosis among postmenopausal women was $43 \%$ in the femoral area and $20 \%$ in the vertebral column [31]. Moreover, in the study by Jamshidian et al., the prevalence of osteoporosis in the femoral area and vertebral column was $15.8 \%$ and $2.9 \%$ [32]. In Pazhouhi et al., the prevalence of osteoporosis in women 10 to 75 years of age in Tehran was 28.1\% [33]. In the study of Aghamohammadzadeh et al., the prevalence of osteoporosis was $26 \%$. On the other hand, in the review of osteoporosis prevalence in the Middle East, it was found that the prevalence of osteoporosis in Saudi Arabia was $33.2 \%$ and $46.5 \%$ in males and females, respectively, while the prevalence of osteopenia in males and females was $44.5 \%$ and $41.4 \%$, respectively [34]. The reasons for justifying the difference in the results from various studies could be due to the type of osteoporosis test, the site of bone density test, the type of device, or the skill of the test interpreter, as well as the race, age, and gender of studied populations in different studies. Since the loss of bone density in spongy bones such as the pelvic bone occurs more rapidly, the lack of consistency between different sites is inevitable and could be due to physiological and pathological factors, or performance and analysis of the test [35].

The results of this study showed that there was a significant statistical relationship between T-score and age groups. Subjects in age group of 51-60 years had the lowest T-score. Similarly, there was a significant relationship between bone density and age group. The highest prevalence of osteoporosis (65.4\%] was in the age group of 51-60 years old. Other studies have also suggested that age is an important factor in the reduction of bone density and consequently the incidence of osteoporosis [33].

In the present study, $19 \%$ of subjects had vitamin D deficiency, $38.8 \%$ of subjects had insufficient levels of vitamin D, and $42.3 \%$ of subjects had sufficient vitamin D levels. A study by Dipak et al. in the United Kingdom, aiming to assess the level of vitamin $\mathrm{D}$ and bone density in 78 Asian women living in England, showed that $96 \%$ of the subjects had vitamin D serum levels of less than $15 \mathrm{ng} / \mathrm{ml}$. In $26 \%$ of the patients, the trend was less than $5 \mathrm{ng} / \mathrm{ml}$ [36]. In the present study, $81.1 \%$ of subjects had vitamin D serum level of less than $15 \mathrm{ng} / \mathrm{ml}$, which was close to the findings of the Dipak et al. study. In a study published by Larijani et al. in 2007, aiming to evaluate the prevalence of osteoporosis and its related risk factors, the prevalence of vitamin D deficiency was $80.7 \%$, vitamin D serum level of less than $5 \mathrm{ng} / \mathrm{mL}$ [3]. This was approximately twice as high as the findings of the present study. The reason for the increased prevalence of vitamin D deficiency in the Larijani study compared to the present study was due to differences in the statistical population. In Larijani et al., 
women over 50 years old were studied, and considering the effect of age on vitamin D deficiency, the result was acceptable. More precisely, the results of our study shows that there is a significant association between the levels of vitamin D and the age groups of the subjects, while the highest prevalence of vitamin D deficiency $(67.1 \%)$ was seen in the age group of 51 to 60 years old. On the other hand, in the Larijani et al. study, only female subjects were included, which could be another reason for the higher prevalence of vitamin D deficiency. Similar results in our study suggests that there is a significant relationship between vitamin $\mathrm{D}$ levels and the gender of the subjects, as the highest prevalence of vitamin D deficiency $(60.5 \%)$ was found in female subjects. Therefore, regardless of the differences between the results of various studies, older age and female gender are two major factors influencing the prevalence of vitamin D deficiency. In other studies, these two variables have been mentioned as factors affecting vitamin D deficiency [37 - 39].

The results of our study demonstrated that the mean \pm SD of vitamin D levels were $5.50 \pm 3.54 \mathrm{ng} / \mathrm{ml}$ in subjects with osteoporosis, $7.83 \pm 4.98 \mathrm{ng} / \mathrm{ml}$ in subjects with osteopenia, and $23.80 \pm 18.42 \mathrm{ng} / \mathrm{ml}$ in subjects with normal bone density. Therefore, the levels of vitamin $\mathrm{D}$ in subjects with osteoporosis were significantly lower than in other groups. Additionally, there was a significant relationship between levels of vitamin $\mathrm{D}$ and the bone density status of the subjects. The prevalence of vitamin D deficiency in subjects with osteoporosis was $44.7 \%$, in subjects with osteopenia was $28.9 \%$, and in subjects with normal bone density was $26.3 \%$. In a study conducted by Vivek et al. in India, aiming to determine the association between vitamin $\mathrm{D}$ levels and bone density in 92 subjects, it was found that vitamin D level had a significant and direct relationship with bone density [39]. This finding was similar to the results of our study. These finding is similar to the results of this study [36].

To summarize, the results of this study indicate that the prevalence of vitamin D deficiency in osteopenic and osteoporotic patients is higher than in normal subjects, which has a significant relationship with age and gender. Furthermore, vitamin D treatment improved bone density indices and reduced the incidence of osteoporosis. It is recommended that continuous and regular treatment with vitamin D supplements be performed, especially in women and the elderly, to prevent and even improve osteoporosis.

\section{Suggestions}

More studies using different doses of vitamin D supplements are recommended for the improvement of bone mineral density indices. Given the fact that this study was conducted on a limited population, further research is recommended, especially in Iranian societies; and it is needed to eliminate the limitations of the study. It is recommended to screen the prevalence of vitamin D deficiency and the prevalence of osteoporosis in order to more quickly identify high-risk patients, and to handle more patients and to treat them faster in order to control them faster and more satisfactorily. More researches are suggested to investigate the relationship between other dietary supplements on the improvement of clinical and laboratory symptoms in people with osteoporosis; and also it seems necessary to identify the best supplements and drugs available to control this severe disorder.

Acknowledgements: This article has been extracted from the dissertation of the doctor of internal medicine Dr. Amir Ghorbani in Semnan University of Medical Sciences. The dissertation was approved as a research project with a registration number in a clinical trial. The researchers would like to express their gratitude to the Research and Technology Deputy of Seman University, and also to the staff and participants who were referred to the Bone Density Clinic of Semnan's Kowsar Hospital.

Funding: Research reported in this publication was supported by a grant [number: A-10-284-2] from the Semnan University of Medical Sciences, Semnan, Iran.

Conflict of interest: The authors declare no conflicts of interest.

\section{References}

1. Xiong J, Onal M, Jilka RL, Weinstein RS, Manolagas SC, O'Brien CA. Matrix-embedded cells control osteoclast formation. Nature medicine. 2011;17(10):1235.

2. Ahlborg HG JO, Turner CH, Rannevik G, Karlsson MK. Bone loss and bone size after menopause. New England Journal of Medicine. 2003;349(4):327-34.

3. Larijani B, Resch H, Bonjour J, Meybodi HA, Tehrani MM. Osteoporosis in Iran, overview and management. Iranian Journal of Public Health. 2007;36(Supple 1):1-13.

4. Mehrabadi F GP M, Asadi, Haqqani. Elderly Styles of Osteoporosis and Related Factors. Elderly Science Research Journal. 2017;12(2):45-132. 
5. Kerman. FDCEAoOSACSo. School of Health Information and Management, Kerman University of Medical Sciences, Kerman, Iran. 2017.

6. Fazaeli AA, Fazaeli AA, Hamidi Y, Moeini B, Valinejadi A. Analysis of iranian household financial participation in the health system: Decomposition of the concentration index approach. Koomesh. 2018:358-68.

7. Yousefi M, Aliani S, Valinejadi A, Rezazadeh A, Khorsand A, Fazaeli S, et al. Effect of" Iran's health system evolution plan" and" tariff change" on financial performance of para-clinic units in a big tertiary hospital in Iran. Koomesh. 2018;20(2):403-409.

8. Shojaei S, Yousefi M, Ebrahimipour H, Valinejadi A, Tabesh H, Fazaeli S. Catastrophic health expenditures and impoverishment in the households receiving expensive interventions before and after health sector evolution plan in Iran: Evidence from a big hospital. Koomesh. 2018:283-90.

9. Valinejadi A, Sadoughi F, Salehi M. Diabetes knowledge translation status in developing countries: A mixed method study among diabetes researchers in case of Iran. International journal of preventive medicine. 2016;7.

10. Larijani B MA, Keshtkar AA, Hossein-Nezhad A, Soltani A, Bahrami A, et al. Peak bone mass of Iranian population: The Iranian multicenter osteoporosis study. Journal of Clinical Densitometry. 2006;9(3):367-74.

11. Heshmat R MK, Majdzadeh S, Forouzanfar M, Bahrami A, Ranjbar Omrani G. Vitamin D deficiency in Iran: A multi-center study among different urban areas. Iran J Public Health. 2008;37.

12. Becker CB, Cohen A, com U. Evaluation and treatment of premenopausal osteoporosis. UptoDate, Basow, DS (Ed), UptoDate, Waltham, MA. 2008.

13. Poole KE, Compston JE. Osteoporosis and its management. Bmj. 2006;333(7581):1251-6.

14. Duncan EL, Danoy P, Kemp JP, Leo PJ, McCloskey E, Nicholson GC, et al. Genome-wide association study using extreme truncate selection identifies novel genes affecting bone mineral density and fracture risk. PLoS genetics. 2011;7(4):e1001372.

15. Kanis JA, Johnell O, Odén A, Johansson H, De Laet C, Eisman J, et al. Smoking and fracture risk: a meta-analysis. Osteoporosis International. 2005;16(2):155-62.

16. Mackey DC, Lui L-Y, Cawthon PM, Bauer DC, Nevitt MC, Cauley JA, et al. High-trauma fractures and low bone mineral density in older women and men. Jama. 2007;298(20):2381-8.

17. Adler RA RCGao. Endocrinology and metabolism clinics of North America. 1994;23(3):641-54.

18. Cummings SR, Nevitt MC, Browner WS, Stone K, Fox KM, Ensrud $\mathrm{KE}$, et al. Risk factors for hip fracture in white women. New England journal of medicine. 1995;332(12):767-74.

19. Laan R, Buijs W, Verbeek A, Draad M, Corstens F, Van de Putte $L$, et al. Bone mineral density in patients with recent onset rheumatoid arthritis: influence of disease activity and functional capacity. Annals of the rheumatic diseases. 1993;52(1):21.

20. Bernstein CN, Leslie WD, Leboff MS. AGA technical review on osteoporosis in gastrointestinal diseases. Gastroenterology. 2003;124(3):795-841.

21. Haworth C, Selby P, Webb A, Dodd M, Musson H, Niven RM, et al. Low bone mineral density in adults with cystic fibrosis. Thorax. 1999;54(11):961-7.
22. Franklyn JA SM. The thyroid and osteoporosis. Trends in Endocrinology \& Metabolism. 1992;3(4):113-6.

23. Vestergaard P. Discrepancies in bone mineral density and fracture risk in patients with type 1 and type 2 diabetes-a meta-analysis. Osteoporosis international. 2007;18(4):427-44.

24. Hruska KA, Teitelbaum SL. Renal osteodystrophy. New England Journal of Medicine. 1995;333(3):166-75.

25. Lips P, Bouillon R, Van Schoor NM, Vanderschueren D, Verschueren S, Kuchuk N, et al. Reducing fracture risk with calcium and vitamin D. Clinical endocrinology. 2010;73(3):277 85.

26. Riggs BL. Overview of osteoporosis. Western journal of medicine. 1991;154(1):63.

27. Kanis J, Burlet N, Cooper C, Delmas P, Reginster J-Y, Borgstrom $\mathrm{F}$, et al. European guidance for the diagnosis and management of osteoporosis in postmenopausal women. Osteoporosis international. 2008;19(4):399-428.

28. Weaver C, Gordon C, Janz K, Kalkwarf H, Lappe J, Lewis R, et al. The National Osteoporosis Foundation's position statement on peak bone mass development and lifestyle factors: a systematic review and implementation recommendations. Osteoporosis International. 2016;27(4):1281-386.

29. Mahdavi-Roshan M, Ebrahimi-Mamghani M, Ebrahimi A, GhaemMaghami J. Nutritional and biochemical factors of zink and calcium in postmenopausal women with osteoporosis in Tabriz-2007. Behbod. 2009;12:296-307.

30. Palacios C, Gonzalez L. Is vitamin D deficiency a major global public health problem? The Journal of steroid biochemistry and molecular biology. 2014;144:138-45.

31. Mojibian M, Oulia M, Beiki BO, Kouchak YL. Osteoporosis in postmenopausal women. 2006.

32. Jamshidian TM KN, Azadbakht L, Rajaie A, Houshyarrad A, Golestan B, et al. The Prevalence of Osteoporosis Among Women Aged 40-60 in Tehran. 2004.

33. Pazhouhi M HA, Soltani A, Maghbooli Z, Madani F. Bone Mnneral Density Variations in 10-7 Years-Old Women Inhabitations of Tehran. 2003.

34. Hadavi L G, Eshraghi, Babak. Prevalence of osteoporosis and T-score mismatch between the spine and femur and some of the factors affecting it in Iran. Journal of Diabetes and Metabolism of Iran. 2015;14(5):14-305.

35. HOSSEINNEZHAD A SA, Adibi H, Hamidi Z, Maghbooli Z. Relationship between life style and bone mineral density in men. 2003.

36. Roy DK, Berry JL, Pye SR, Adams JE, Swarbrick CM, King Y, et al. Vitamin D status and bone mass in UK South Asian women. Bone. 2007;40(1):200-4.

37. Haden S, Fuleihan G, Angell J, Cotran N, LeBoff M. Calcidiol and PTH levels in women attending an osteoporosis program. Calcified tissue international. 1999;64(4):275-9.

38. Chapuy M-C, Preziosi P, Maamer M, Arnaud S, Galan P, Hercberg $S$, et al. Prevalence of vitamin D insufficiency in an adult normal population. Osteoporosis international. 1997;7(5):439-43.

39. Arya V, Bhambri R, Godbole MM, Mithal A. Vitamin D status and its relationship with bone mineral density in healthy Asian Indians. Osteoporosis international. 2004;15(1):56-61. 